\title{
Progress and prospects of biological approaches targeting PCSK9 for cholesterol-lowering, from molecular mechanism to clinical efficacy
}

Amir Mohammad Malvandi , Laura Canclini , Anxhela Alliaj , Paolo Magni , Alberto Zambon \& Alberico Luigi Catapano

To cite this article: Amir Mohammad Malvandi , Laura Canclini , Anxhela Alliaj, Paolo Magni , Alberto Zambon \& Alberico Luigi Catapano (2020): Progress and prospects of biological approaches targeting PCSK9 for cholesterol-lowering, from molecular mechanism to clinical efficacy, Expert Opinion on Biological Therapy, DOI: 10.1080/14712598.2020.1801628

To link to this article: https://doi.org/10.1080/14712598.2020.1801628

Accepted author version posted online: 27

Jul 2020.

Published online: 04 Aug 2020.

Submit your article to this journal $\widetilde{ }$

凹 Article views: 12

Q View related articles $\sqsubset$

View Crossmark data $₫$ 


\title{
Progress and prospects of biological approaches targeting PCSK9 for cholesterol- lowering, from molecular mechanism to clinical efficacy
}

\author{
Amir Mohammad Malvandi $\mathbb{1}^{\mathrm{a}}$, Laura Canclini ${ }^{\mathrm{a}, \mathrm{b}}$, Anxhela Alliaj ${ }^{\mathrm{a}}$, Paolo Magnia, ${ }^{\mathrm{a}}$, Alberto Zambon ${ }^{\mathrm{a}, \mathrm{c}}$ \\ and Alberico Luigi Catapano ${ }^{\mathrm{a}, \mathrm{b}}$
}

${ }^{a}$ RCCS Multimedica, Milan, Italy; 'b Department of Pharmacological and Biomolecular Sciences, Università degli Studi di Milano, Milan, Italy; 'Department of Medicine, Università degli Studi di Padova, Padua, Italy

\section{ABSTRACT}

Introduction: Cardiovascular disorders are one of the leading causes of mortality and morbidity worldwide. Recent advances showed a promising role of proprotein convertase subtilisin/kexin type 9 (PCSK9) as a critical player in regulating plasma LDL levels and lipid metabolism.

Areas covered: This review addresses the molecular functions of PCSK9 with a vision on the clinical progress of utilizing monoclonal antibodies and other biological approaches to block PCSK9 activity. The successful clinical trials with monoclonal antibodies are reviewed. Recent advances in (pre)clinical trials of other biological approaches, such as small interfering RNAs, are also discussed.

Expert opinion: Discovery of PCSK9 and clinical use of its inhibitors to manage lipid metabolism is a step forward in hypolipidaemic therapy. A better understanding of the molecular activity of PCSK9 can help to identify new approaches in the inhibition of PCSK9 expression/activity. Whether if PCSK9 plays a role in other cardiometabolic conditions may provide grounds for further development of therapies.
ARTICLE HISTORY

Received 8 June 2020

Accepted 23 July 2020

KEYWORDS

PCSK9; monoclonal antibodies; cholesterollowering; metabolic regulation

\section{Introduction}

PCSK9 is a protein from the family of secretory proteases responsible for the proteolytic activation of protein precursors [1]. PCSK9 is mainly produced within the hepatocyte; however, other cell types can produce and secrete the protein, whether this extrahepatic production has a systemic role remains to be addressed [2]. The PCSK9 protein consists of 692-aminoacids, including a signal peptide, a pro-domain, a subtilisin-like catalytic domain and a variable C-terminal domain. Two forms of PCSK9 are found in plasma, a $63 \mathrm{kDa}$ and $55 \mathrm{kDa}$ protein [3]. The mature protein of $63 \mathrm{kDa}$ is produced in the endoplasmic reticulum (ER) as a result of the removal of pro-PCSK9's signal peptide followed by autocatalytic cleavage of the pro-domain, which in turn can associate to the catalytic domain inhibiting PCSK9 activity [4]. The 52-55 kDa truncated type is generated mainly by furin cleavage after release; these lower molecular weight forms appear to have lower affinity to the LDLR [3], but still, the possible physiological function of this form of PCSK9 is not clear [5]. Near to half of the circulating PCSK9 appears to be the truncated form [6], while the total protein level in plasma may widely vary in the population over a 100 -fold range (33-2988 ng/mL), with a median value of $487 \mathrm{ng} / \mathrm{mL}$ [7]. This wide range is, in part, explained by gender [7], fasting state [8], time of the day [8], lifestyle [9], diet [10] and disease conditions [7]; of note, PCSK9 is also responding as an acute phase reacting protein [11].

Due to PCSK9 activity in the metabolism of low-density lipoprotein ( $L D L)$, it has become a target for treatment of hypercholesterolemia [12]. This function has first emerged by identifying an autosomal dominant familial hypercholesterolemia (FH) result of the Gain-of-function (GOF) mutations in the PCSK9 gene [13]. Further evidence confirmed this observation by the identification of Loss-of-function (LOF) mutations in the PCSK9 gene, which correlates with a phenotype characterized by low LDL plasma levels and decreased cardiovascular risk [14]. The efficiency of PCSK9 to orchestrate the LDL levels in blood relates to its association with the turnover of the LDL receptor (LDLR) since the cellular uptake of LDL is mainly receptor-dependent [15]. When PCSK9 binds to the epidermal growth factor-like repeat domain of the LDLR, the LDL-LDLR complex cannot unfold in the endosomes and undergoes lysosomal degradation [16]. The reduction of the surface LDLR results in increased plasma LDL levels while lowering plasma levels of PCSK9 results in an increased presence at the surface of the cells of the LDL receptor and as a consequence in the reduction of circulating LDL particles $[17,18]$.

Currently, monoclonal antibodies (mAbs) is the only clinically available pharmacological approach targeting PCSK9 to treat hypercholesterolemia [19]. Several other therapeutic approaches have been proposed for suppressing or inhibiting PCSK9 (Figure 1), including gene silencing agents such as siRNA [20] or antisense oligonucleotides [21], small peptides or adnectins [22], and small molecules [23]. A PCSK9 vaccine is also under evaluation [24]. This review covers the state of the art regarding the action of PCSK9 on lipoprotein metabolism 


\section{Article highlights}

- PCSK9 is a small protein produced mainly by hepatocytes, which has a crucial role in modulating the clearance of LDL from plasma.

- The LDL receptors (LDLR) that have PCSK9 bound will be degraded in lysosomes, and this reduction of LDLR increases the levels of LDL in plasma.

- Blocking PCSK9 either in function (with monoclonal antibodies) or at its expression level (with small RNAs or other biological agents) can significantly reduce the plasmatic LDL-C levels and, therefore, cardiovascular risks.

- The translation from bench to clinical usage of monoclonal antibodies to block PCSK9 is one of the fastest in the history of drug development, due to its efficient and specific function on LDLR turnover.

This box summarizes key points contained in the article.

and the potential of new biological approaches to lower PCSK9 and to reduce LDL cholesterol.

\section{PCSK9 and LDL metabolism}

The clearance of LDL from plasma mainly occurs in hepatocytes throughout the LDLR mediated endocytosis [29]. PCSK9 has a direct effect on LDLR; but it can target other receptors as well; for instance, human embryonic kidney cells (HEK293) incubated with conditioned media containing recombinant PCSK9 showed decreased levels of receptors belonging to the LDLR family that modulate the clearance of TG-rich lipoproteins (VLDL and apolipoprotein $E_{2}$ (ApoE) receptors), probably due to mechanisms involved in the lysosomal degradation pathway [30]. A link has also been reported between PCSK9 and apoB-100 secretion from the liver of $\mathrm{FH}$ patients carrying the GOF S127R mutation in PCSK9, which seems to increase the level of ApoB-100, leading to increase in VLDL, remnants and LDL plasma levels [31]. This effect on ApoB secretion could be a result of PCSK9mediated degradation of LDLR and the consequently reduced LDL clearance rate, but it is also possible that PCSK9 may affect $A p o B$ by binding to its $\mathrm{N}$-terminal domain preventing $A p o B$ autophagy [32]. The autophagosome/lysosome pathway is an LDLR-independent mechanism proposed for the intracellular degradation of $A p o B$, since the interaction with PCSK9 could shunt $A p o B$ from degradation in autophagosome, destinating it for assembly of VLDL in hepatocytes [32]. In vitro studies showed that $A p o B$ secretion is also stimulated in human enterocytes (CaCo-2 cells) throughout LDLR dependent and independent mechanisms, involving both transcriptional and posttranscriptional effects on ApoB production, stability and degradation [33].

This evidence suggests that PCSK9 plays a central role in modulating plasma lipoprotein profile, particularly LDL, but other lipoproteins could be affected as well.
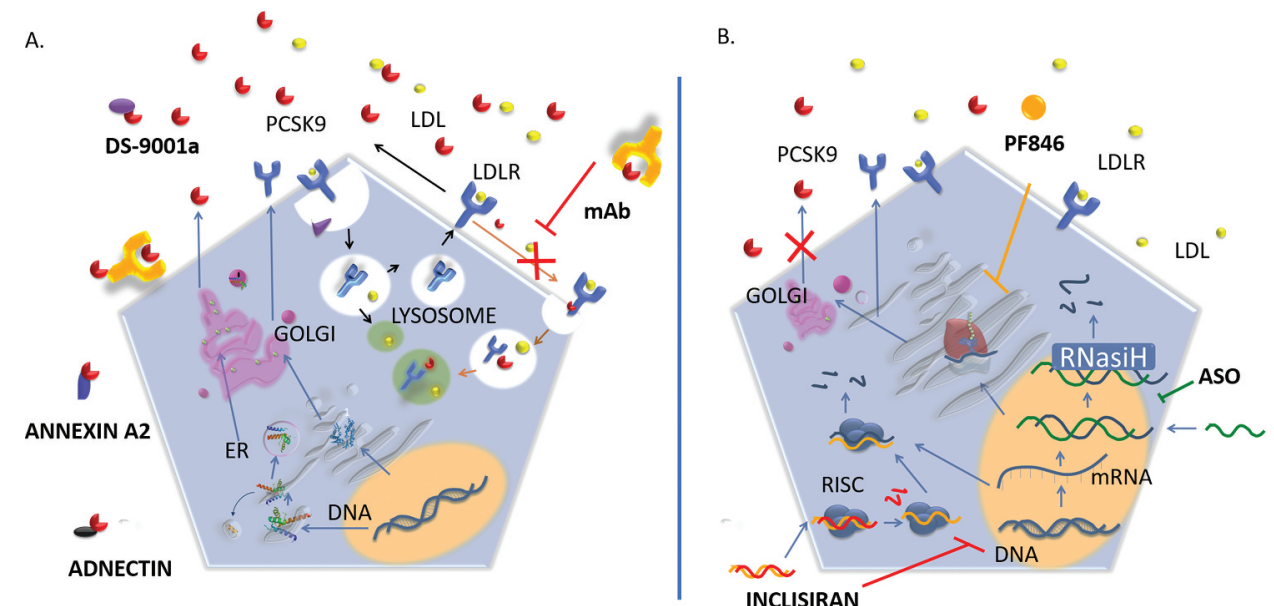

Figure 1. Different biological strategies to target PCSK9. To reduce the plasmatic LDL-C level, we can suppress the PCSK9 function ( $A$ ). As the current approach in the clinics, the binding of mAbs to free PCSK9 in plasma prevents the binding to the LDLR, increasing its expression. The anti-PCSKO MAbs bind to the catalytic domain of PCSK9 by neutralizing PCSK9 blocking the extracellular interaction with the EFG-A domain of LDLR [25]. Other approaches in this category are; (1) Annexin $-A 2$ is an extracellular endogenous antagonist that specifically binds to the C-terminal domain of the PCSK9 at the cell surface, inhibiting the PCSK9-mediated degradation of LDRL. Adenoviral overexpression of AnxA2 in the liver results in an increase of LDLR expression [26]; (2) DS-9001a is a small biologic molecule, composed of an albumin-binding domain fused with an artificial lipocalin mutein enabling high specific recognition of the target protein. DS-9001a inhibits the binding of the PCSK9 to LDLR, preventing LDLR degradation [27]; (3) Adnectin, BMS-962,476 is a PCSK9-targeting polypeptide conjugated with polyethylene glycol which enhances its pharmacokinetic profile, binding to human PCSK9 with subnanomolar affinity. Adnectin hinders the interaction between the EGF-A domain of LDLR and extracellular PCSK9, thus preventing the PCSK9- induced degradation of LDLR [28]. Instead of biologically blocking the PCSK9 function, we can block its production at the transcript level (B). To reach this aim, there has been in clinical trial different approaches; (1) Inclisiran is a fully chemically modified and liverspecific siRNA directed against PCSK9. Inclisiran is composed of one 2'-deoxy, eleven 2'-fluoro-, and thirty-two 2'-0- methyl-modified nucleotides, and a triantennary $\mathrm{N}$-acetylgalactosamine (GaINAc) that is conjugated to the $3^{\prime}$-end of the passenger strand. The asialoglycoprotein receptor recognizes the GALNAc inhibiting the uptake of Inclisiran, resulting in the reduction of PCSK9 mRNA by 70\% [113]; (2) Antisense Oligonucleotides (ASOs) inhibit the PCSK9 mRNA protein synthesis decreasing intra and extracellular protein levels. SPC5001, the clinical grade product of this approach, is 14 base oligonucleotide relying on locked nucleic acid technology with higher binding and specificity for PCSK9 mRNA [12]; (3) it has been proposed to block the PCSK9 expression by targeting the ribosomal complex using biologically active small molecules, in this way PF-06446846 (PF846) a small active molecule has been developed that directly inhibits the translation of PCSK9 by stalling the $80 \mathrm{~S}$ ribosome in codon 34. The activity depends on the sequence of the nascent chain within the ribosome exit tunnel [14]. 


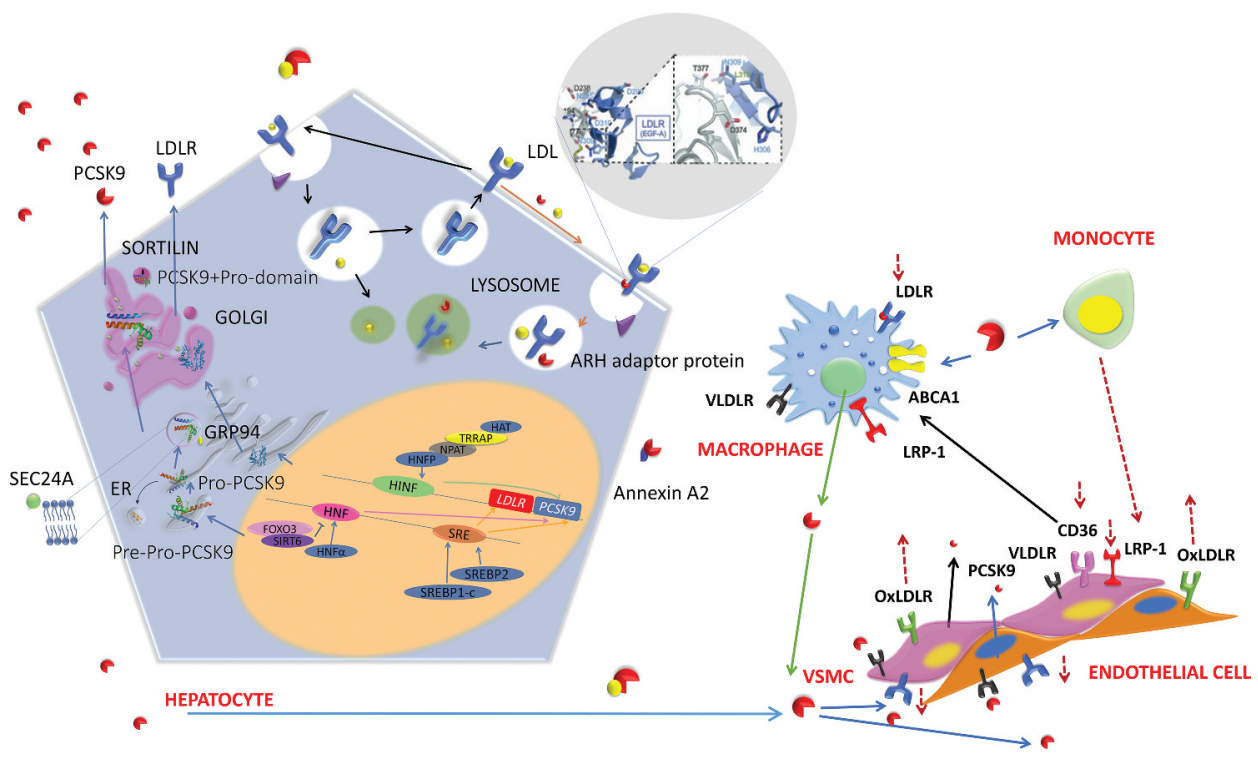

Figure 2. PCSK9 turnover in circulation and its metabolic function. Hepatocyte: LDLR activity in the absence of PCSK9 (black arrow): LDLR binds LDL and the complex is internalized by endocytosis. ARH is an adaptor protein that participates in the internalization of the LDL-LDLR complex. After this step, LDL is degraded into lysosomes while LDLR is recycled to the membrane; LDLR activity in the presence of PCSK9 (orange arrow): on the cell surface, PCSK9 binds to LDLR. The complex is internalized and degraded into lysosomes, preventing LDLR recycling to the membrane. HMSCs, ECs and macrophages produce PCSK9, although most of the protein comes from hepatocytes. Apart from hepatic effects, PCSK9 has other pleiotropic effects (dotted arrow) on the cells of the plaque. If internalized by macrophages, it could prevent the foam cell formation, acting on the clearance of the LDLR. PCSK9 can also modulate the recruitment of monocyte in the atherosclerotic plaque. It is also able to induce the expression of the OxLDLr on ECs and HSMCs surface. In HSMCs, PCSK9 has been shown to downregulate the expression of receptors such as LRP-1, CD36, and LDLR. 3D structural demonstration of EGF-A domain of LDLR is adopted from [46].

\section{PCSK9 gene regulation}

The interaction of PCSK9 and LDL metabolism (Figure 2) is reciprocal; for instance, cholesterol deficiency or inhibition of intracellular cholesterol biosynthesis (as it happens with statins) upregulates PCSK9 throughout the recruitment of sterolregulatory element-binding protein 1 (SREBP1) and SREBP2 that bind to the sterol-regulatory element (SRE) in the proximal promoter region of the gene [34]. Dietary Saturated Fatty acids (SFAs) upregulate SREBP2 that increases PCSK9 expression, while long-chain polyunsaturated fatty acids ( $n-3$ PUFA) down-regulate SREBP2 probably due to modulating the phosphorylation of the mitogen-activated protein kinases (MAPKs) [10]. The administration of $n-6$ PUFA has been reported to reduce PCSK9 expression, by reducing inflammatory responses, via reduction of the expression of the tumor necrosis factor receptor 2 (TNF-R2) and interleukin-1 (IL-1) which upregulate SREBP2 [35]. The same effect has been reported for monounsaturated fatty acids (MUFAs) that can have antiinflammatory effects [36]. Fasting state also decreases PCSK9 and cholesterol biosynthesis, probably by downregulating SREBP2 [8]. Additionally, PUFAs can activate the peroxisome proliferator-activated receptors a (PPARa), leading to suppression of PCSK9 promoter's activity and SREBP1c expression [37]. Following this, the activation of the Janus kinase/signal transducer and activator of transcription (JAK/STAT) pathway suppresses PCSK9 expression [38] while its inhibitor, the suppressor of cytokine-signaling-3 (SOC3), stimulates PCSK9 expression throughout the activation of SREBP1 [39], thus reinforcing the link between PCSK9 and inflammation. Glucagon reduces hepatic PCSK9 and SREBP2 expression [40]. This observation suggests that other regulatory elements additional to SRE may be present in the PCSK9 gene promoter. In this way, hepatic nuclear transcription factor protein a (HNFa) has been found as another factor promoting PCSK9 transcription by binding to an HNF binding motif, located 28 base pairs upstream of the SRE site [41]. Insulin inhibits the HNF-induced PCSK9's transcription by $\mathrm{FoxO}_{3}$ recruitment of sirtuin 6 -a protein deacetylase- in a region wholly embedded in the HNF1A binding site [42]. Insulin represses hepatic PCSK9 expression mediated by HNF4a and HNF1 also in a protein kinase C-dependent manner [43]. The histone nuclear factor $P$ (HNFP) region cooperates as well in PCSK9 transcriptional regulation [44]. Here, a complex composed of HINFP and its cofactor nuclear protein of the ataxia telangiectasia mutated locus (NPAT) recruits the histone acetyltransferase (HAT) cofactor transformation/transactivation domain-associated protein (TRRAP), that facilitate the histone $4(\mathrm{H} 4)$ acetylation in the PCSK9 promoter [45]. Current evidence indicates that the SRE motif in the promotor principally regulates PCSK9 expression; however, there are other elements on its adjacent upstream region that cooperate in the regulation. It is also clear that PCSK9 expression does not only depend on lipid metabolism but also factors related to glycemia and inflammation; PCSK9 potential role in these areas is worth investigating.

\section{PCSK9 translation and secretion}

PCSK9, like other zymogens, passes the ER and the Golgi apparatus to become a mature functional protein [47]. The LDLR undergoes the same path and co-exists with PCSK9 in this secretory pathway without being affected; GRP94 is the ER-resident chaperon protein that prevents early binding of 
the LDLR to PCSK9 [48]. Following synthesis in the ER, PCSK9 is transported to the Golgi apparatus into vesicles coated with the coat protein complex II (COPII), where the assembly relies on specific signals within cargo molecules, mediated by the SEC24 subunit of the COPII complex [49]. In mice, homozygous SEC24A deletion results in a phenotype characterized by upregulation of the LDLR and significantly lower LDL-C levels, a consequence of PCSK9 dependence on SEC24A to transit from the ER [50], thus suggesting SEC24A as a possible biological target to reduce LDL. Gustafsen et al. reported a potential effect of Sortilin, a protein encoded by the hypercholesterolemia-risk gene SORT1 in modulating PCSK9 secretion, as the two proteins colocalize in the trans-Golgi network [51]. Further research is warranted to elucidate the interaction of PCSK9 with Sortilin (Figure 2).

Annexin A2 (AnxA2) has been identified as an endogenous extrahepatic inhibitor of PCSK9. Extracellular AnxA2 is a membrane-associated receptor for several proteins that hampers PCSK9 binding to the LDLR interacting with its C-terminal CysHis-rich domain (CHRD), probably through the induction of allosteric structural changes [52]. It is highly abundant at the surface of endothelial cells, fibroblasts and COS-7 cells, thus explaining in the inability of high concentrations of injected PCSK9 to promote LDLR degradation in these cells [52]. Altogether these findings show the potential for alternative targets to modulate PCSK9 levels.

\section{Monoclonal antibodies for cholesterol-lowering}

The discovery of the PCSK9 function in lipid metabolism has triggered the development of pharmacological strategies to decrease PCSK9 levels by targeting either protein synthesis or its interaction with the LDLR. Treatment with mAbs is currently one of the best clinical strategies to deal with severe hypercholesterolemia [53]. The use of mAbs for blocking PCSK9 has been one of the fastest translations to the clinic in the history of drug development (Figure 3). From the development of the first successful clinical-grade monoclonal antibodies, it took only a few years for the FDA and EMA approval for therapy
[54]. Alirocumab and evolocumab are two fully human monoclonal antibodies currently approved for therapy. Antibodybased therapy has advantages over traditional therapies in terms of specificity, potency and posology. mAbs do not interact with cytochromes or other proteins, leading to a reduced risk of drug-drug interactions [19].

Alirocumab is a monomeric immunoglobulin $\mathrm{G} 1$ (lgG1) isotype; it is composed of two human heavy chains, two kappa light chains and a single glycosylation site. At low concentrations, its elimination predominately occurs through saturable binding to PCSK9, while at higher concentrations it depends on a non-saturable proteolytic pathway; resulting in a median half-life at steady state of 17 to 20 days in monotherapy if administered once every two weeks (75 or $150 \mathrm{mg}$ ) [59].

Evolocumab is a dimeric immunoglobulin G2 (lgG2) isotype [60] composed of two lambda light chains and two heavy chains with glycosylated sites [61]. The recommended therapy regime for evolocumab is $140 \mathrm{mg}$ every two weeks or $420 \mathrm{mg}$ monthly administration [62]. It has two elimination phases, while it has an estimated half-life is 11-17 days [60]. A negligible amount of anti-drug antibodies has been reported for evolocumab treated patients [63].

\subsection{Clinical trials}

After different preclinical and Phase I trials, Phase II clinical trials ended in 2012 and confirmed the encouraging results of the previous phases. Both alirocumab and evolocumab were shown to reduce LDL-C plasma levels alone successfully or in combination with different doses of statins and/or Ezetimibe (Table 1).

The OSLER 1 and 2 trials with an open-label randomized controlled approach examined evolocumab [70]. They included patients with other cardiovascular risk factors showing a reduction in LDL-C levels of about $61 \%$ (Table 2). A similar investigation was conducted for alirocumab on the ODYSSEY LONG TERM study, with comparable results [71]. However, the first randomized controlled cardiovascular outcome trial for evolocumab was FOURIER [72]. The 27,564

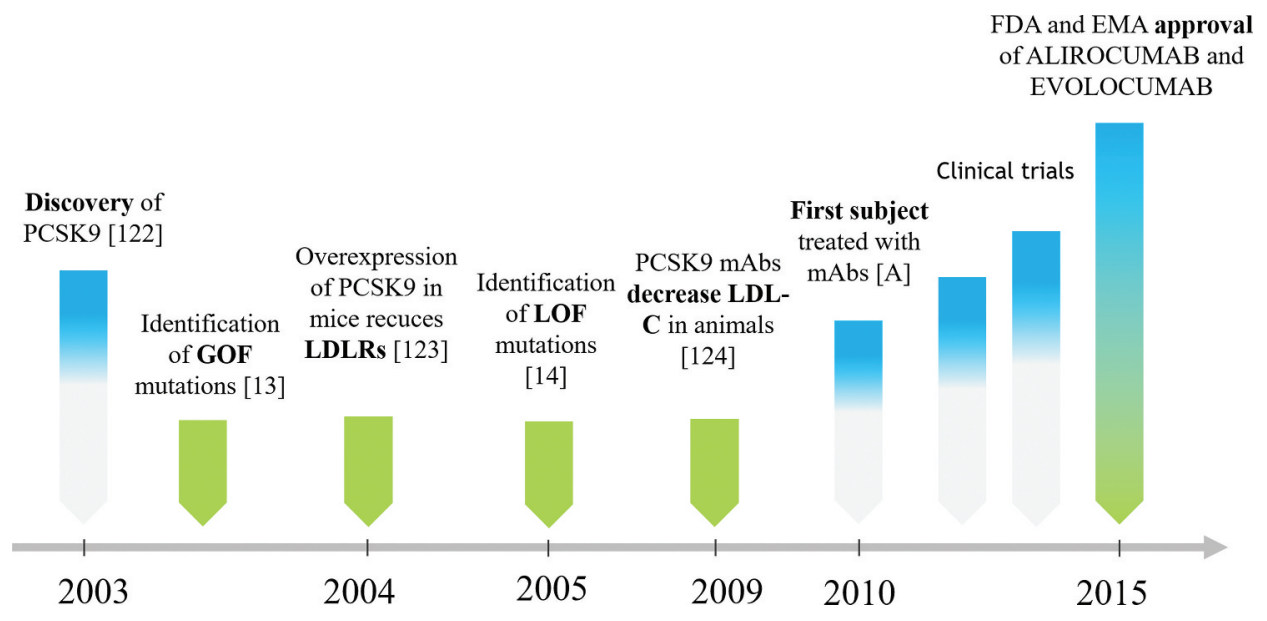

Figure 3. Time-line of PCSK9: from discovery to therapy. [55; 13; 56; 14; 57]; [A = Sanofi report]; [58]. 
Table 1. Phase II clinical trials with alirocumab or evolocumab. Summary of experimental designs and their endpoint in the reduction of LDL-C plasma levels, the presence or absence of different adjunctive ad-hoc lipid-lowering therapies. The total recruited individuals in all of the trials were 1701.

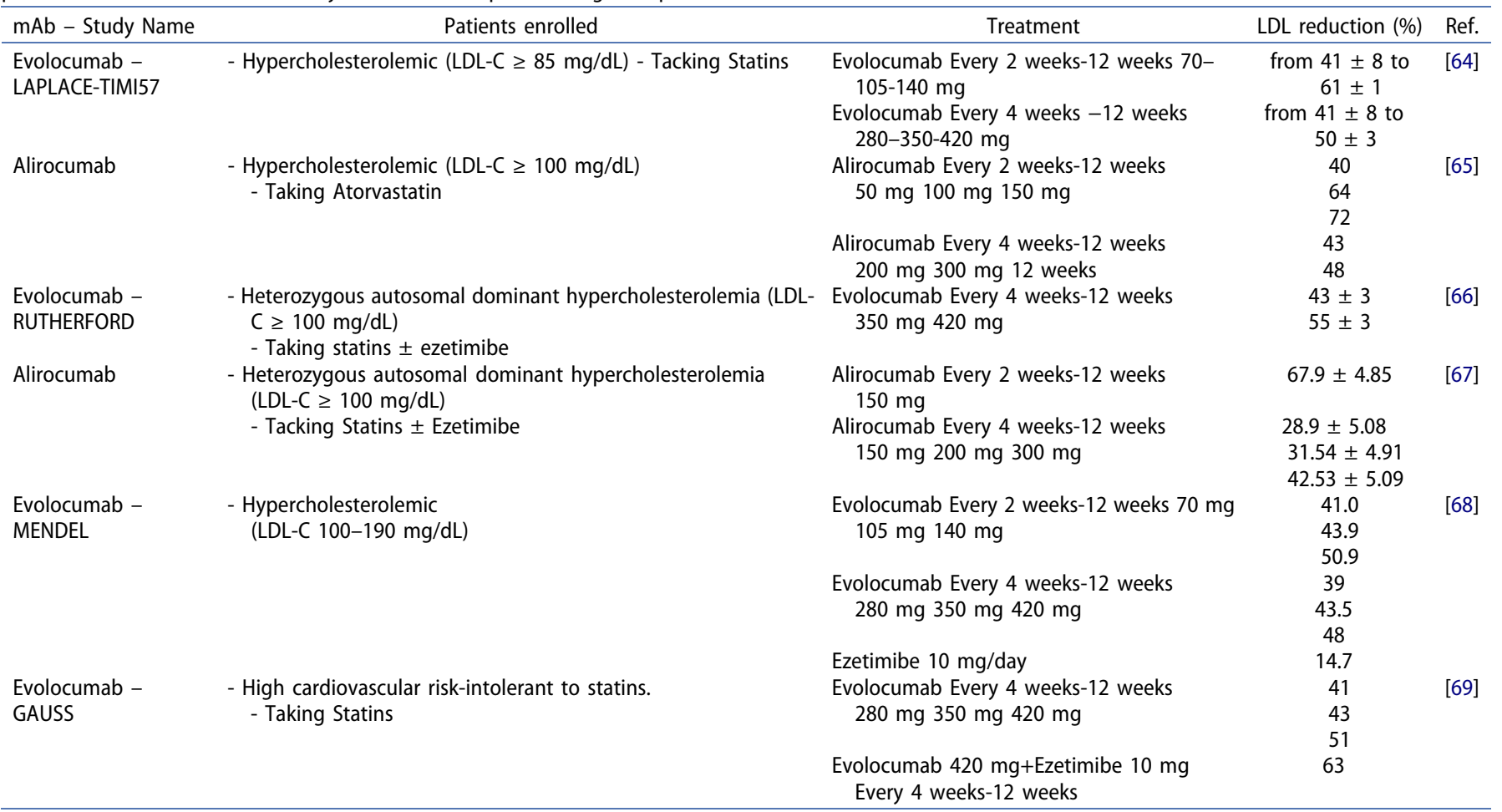

patients with established atherosclerotic cardiovascular disease on statin therapy were randomized to either evolocumab or placebo and monitored for the rate of major cardiovascular events. At 48 weeks, patients on evolocumab showed a $59 \%$ reduction in LDL-C as compared with those on statin therapy; after 26 months, evolocumab was associated with a $1.5 \%$ absolute risk reduction in the primary outcome. These effects were consistent regardless of baseline cholesterol levels or statin dose. The subsequent analysis assessed the efficacy and safety of evolocumab according to the degree of LDL-C reduction at one month [73]. Further subanalysis studies confirmed benefit from evolocumab treatment also in patients with myocardial infarction (MI) [74] and peripheral arterial disease (PAD) [75]. Then, The ODYSSEY OUTCOMES trial enrolled 18,924 subjects within 112 months after acute coronary syndrome (ACS) after a run-in phase of 2-16 weeks on high-intensity statin therapy. Individuals with $\mathrm{LDL}-\mathrm{C} \geq 70 \mathrm{mg} / \mathrm{dL}$ were randomized to alirocumab or placebo. Alirocumab injection reduced LDL-C by $54.7 \%$, thus reducing up to $15 \%$ cardiovascular risk if compared with the placebo group [76]. SPIRE1 and 2 clinical trials (funded by Pfizer) have set to evaluate a humanized monoclonal antibody anti PCSK9, bococizumab, on patients at high cardiovascular risk. The trials have been stopped early due to development of anti-drug antibodies nevertheless the LDL-C reduction levels correlated well with the reduction of CVD risk on the patients with high CVD risk and high LDL-C values [77].

This data showed mAbs as monotherapy alone or in association with statins could lead to an up to $65 \%$ reduction in LDL-C plasma levels, thus reducing cardiovascular risk. The absolute reduction of cardiovascular risk, however, directly relates to the absolute reduction (not \%) of LDL-C in plasma [17]. Therefore, in the ODYSSEY OUTCOMES trial, patients treated with alirocumab for a median of 33 months showed $1.1 \mathrm{mmol} / \mathrm{L}$ reduction in LDL-C level that it can be considered up to $22 \%$ reduction in risk for cardiovascular events [83]. Moreover, a $25 \%$ lipoprotein little (a) (Lp(a)) reduction has been observed in alirocumab and evolocumab treated patients at long term follow up [84]; probably due to the similarities between LDL and $\operatorname{Lp}(\mathrm{a})$, it can be catabolized using LDLR-mediated pathway, this possibility, however, remains to be addressed. Further follow-up is essential to clarify mAbs' long-term safety and efficacy.

\subsection{Adverse events}

The potential adverse effects of achieving long-term deficient LDL-C levels in subjects on PCSK9 inhibitors (PCSK9i) have been evaluated. Bococizumab injections (at a substantial part of patients who received the mAbs) induced a high level of anti-drug antibodies (ADAs) titer that lead to significant suppression of PCSK9 inhibition [85]. As well, around $5 \%$ of patients who received alirocumab developed anti-drug antibodies -a percentage that was furthermore reduced to $1.3 \%$-, but without alteration in the LDL-C reduction rate [86]. According to the OSLER-1 long term trial, transient ADAs rarely occurred in patients taking evolocumab, and none was detected after the first-year treatment [63]. There were not significant neurocognitive disorders caused by evolocumab (EBBINGHAUS [70], REGARDS [87]), 


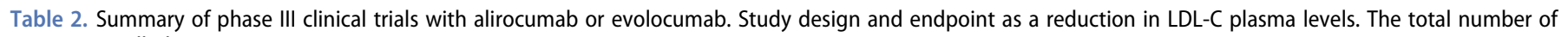
patients enrolled: 4581.

\begin{tabular}{|c|c|c|c|c|}
\hline mAb - Study Name & Patients enrolled & Treatment & LDL reduction (\%) & Ref. \\
\hline $\begin{array}{l}\text { Evolocumab- } \\
\text { MENDEL II }\end{array}$ & Fasting LDL-C 100-190 mg/dL. & $\begin{array}{l}\text { Evolocumab } 140 \mathrm{mg} / \text { Ezetimibe } \\
\text { Every } 2 \text { weeks }-12 \text { weeks } \\
\text { Evolocumab } 420 \mathrm{mg} / \text { Ezetimibe Every } \\
4 \text { weeks }-12 \text { weeks }\end{array}$ & $\begin{array}{l}55-57 \text { more than placebo } \\
38-40 \text { more than ezetimibe }\end{array}$ & [62] \\
\hline $\begin{array}{l}\text { Evolocumab- } \\
\text { LAPLACEII }\end{array}$ & $\begin{array}{l}\text { - Subjects not taking a statin LDL-C of at } \\
\text { least } 150 \mathrm{mg} / \mathrm{dL} \\
\text { - Subjects on a non-intensive statin with LDL- } \\
\mathrm{C} \geq 100 \mathrm{mg} / \mathrm{dL} \\
\text {-Subjects on an intensive statin with LDL-C } \geq 80 \mathrm{mg} / \\
\text { dL }\end{array}$ & $\begin{array}{l}\text { Evolocumab } 140 \mathrm{mg}+\text { Statin Every } \\
2 \text { weeks } 12 \text { weeks vs. placebo or } \\
\text { Ezetimibe } \\
\text { Evolocumab } 420 \mathrm{mg}+\text { Statin } \\
\text { Every } 4 \text { weeks } 12 \text { weeks vs. placebo or } \\
\text { Ezetimibe }\end{array}$ & $66-75$ vs. placebo & [78] \\
\hline $\begin{array}{l}\text { Evolocumab - } \\
\text { DESCARTES }\end{array}$ & $\begin{array}{l}\text { - Fasting } \mathrm{LDL}-\mathrm{C} \geq 75 \mathrm{mg} / \mathrm{dL} \text { and meeting the following } \\
\text { LDL-C values on background lipid-lowering therapy: } \\
-<100 \mathrm{mg} / \mathrm{dL} \text { for subjects with CHD or CHD risk } \\
\text { equivalent } \\
-<130 \mathrm{mg} / \mathrm{dL} \text { for subjects without diagnosed CHD or } \\
\text { CHD risk equivalent }\end{array}$ & $\begin{array}{l}\text { Evolocumab } 420 \mathrm{mg} \text { Once a month } \\
52 \text { weeks }\end{array}$ & $57 \pm 2.1$ & [79] \\
\hline $\begin{array}{l}\text { Evolocumab- } \\
\text { GAUSS2 }\end{array}$ & $\begin{array}{l}\text { - No statin or low dose of Statin with stable } \\
\text { - History of intolerance to at least } 2 \text { Statins } \\
\text { - Subject not at LDL-C goal }\end{array}$ & $\begin{array}{l}\text { Evolocumab } 140 \mathrm{mg} \text { Every } 2 \text { weeks } \\
12 \text { weeks vs. placebo or Ezetimibe } \\
\text { Evolocumab } 420 \mathrm{mg} \text { Every } 4 \text { weeks } \\
12 \text { weeks vs. placebo or ezetimibe }\end{array}$ & $\begin{array}{l}\text { 53-56 from baseline, } \\
\text { corresponding to } 37-39 \text { vs. } \\
\text { ezetimibe }\end{array}$ & [80] \\
\hline $\begin{array}{l}\text { Evolocumab - } \\
\text { RUTHERFORD }\end{array}$ & $\begin{array}{l}\text { - Diagnosis of heterozygous familial } \\
\text { hypercholesterolemia } \\
\text { - Fasting LDL-C } \geq 100 \mathrm{mg} / \mathrm{dL} \\
\text { - Taking Statin or other lipid-lowering therapies }\end{array}$ & $\begin{array}{l}\text { Evolocumab Every } 2 \text { weeks } 12 \text { weeks vs. } \\
\text { placebo } \\
\text { Evolocumab Every } 4 \text { weeks } 12 \text { weeks vs. } \\
\text { placebo }\end{array}$ & $\begin{array}{l}59,2 \\
61,3\end{array}$ & [81] \\
\hline $\begin{array}{l}\text { Alirocumab- } \\
\text { ODISSEY- } \\
\text { ALTERNATIVE }\end{array}$ & $\begin{array}{l}\text { - Primary hypercholesterolemia } \\
\text { - Statin intolerance }\end{array}$ & $\begin{array}{l}\text { Alirocumab } 75 \mathrm{mg} \text { Every } 2 \text { weeks } \\
24 \text { weeks } \\
\text { Ezetimibe } 10 \mathrm{mg} / \mathrm{d} 24 \text { weeks } \\
\text { Atorvastatin } 20 \mathrm{mg} / \mathrm{d} 24 \text { weeks }\end{array}$ & $\begin{array}{l}45 \pm 2.2 \text { (Alirocumab) vs. } \\
14.6 \pm 2.2 \text { (Ezetimibe) } \\
\text { Mean difference: } 30.4 \pm 3.1\end{array}$ & [82] \\
\hline
\end{tabular}

without correlations between the risk of dementia and low LDL-C.

Regarding alirocumab, cognitive disorders were reported of about $0.9 \%$ in patients treated vs. $0.7 \%$ with placebo. Clinical trials of PCSK9i did not show signals of new-onset diabetes, though their median follow-up is relatively short $[88,89]$. Three recent mendelian randomizations studies suggested that longterm lack of PCSK9 activity (genetically dysfunction) may predispose an increased risk of type 2 diabetes mellitus [90-92]. A recent study in mice showed that even if PCSK9 LOF genetic variants are associated with higher plasma glucose levels and increased risk of type 2 diabetes, anti-PCSK9 therapies might have a limited effect on the incidence of diabetes. It is because PCSK9 controls LDLR expression in pancreatic beta-cell, but this effect is most probably correlated to locally produced PCSK9 [93]; since mAbs target mainly circulating PCSK9, they might have a limited impact on beta-cell dysfunction. However, in diabetic patients, it would be interesting to evaluate how the PCSK9i correlates with the effects of anti-diabetic agents [94] on the pancreatic beta cells.

\subsection{Cost-effectiveness}

According to EAS/ESC guidelines, the treatment algorithm for pharmacological LDL-C lowering is utilizing statins as the first-line treatment at the highest tolerated dose. However, if the goal is not reached, ezetimibe is recommended to reach the level of $\mathrm{LDL}-\mathrm{C}<55 \mathrm{mg} / \mathrm{dL}$ [95]. Furthermore, if the combination of statin and ezetimibe does not achieve the LDL-C goal level, PCSK9i treatment could be initiated in primary prevention patients at very high risk, but without $\mathrm{FH}$; and in secondary prevention in patients at very high risk. The effectiveness of PCSK9i (currently in use alirocumab and evolocumab), proved the reduction of LDL-C levels by $50-60 \%$, with an improvement of cardiovascular outcomes and without adverse events [91]. However, due to their high costs, the use of PCSK9i is limited only when first-line treatment did not obtain the desirable effects. Based on estimated costs of PCSK9i, 14,000 USD per person per year in the US and 5,000-7,000 USD per person per year in Europe, the treatment is not considered to be cost-effective for all the patients [96]. The data from FOURIER study suggest that the costs should be reduced by $71 \%$ to be considered cost-effective [97]. Hence, real case data in the Italian population showed consumption of lipid-lowering agents in 2018 stood at 92.5 defined daily dose (DDD)/ 1000 inhabitants per day, with an increase of $4.2 \%$ respect to 2017 and $20 \%$ in comparison with 2013. Notably, significant increases are observed for ezetimibe alone or in association (+13.2\%) and for PCSK9i (+264.8\%). In 2018 statins remained in first place in terms of expenditure/capita (7.89 $€ /$ capita), showing a decrease in costs both when they are used as monotherapy or in association with other lipid modifiers (Tables 3 and 4) [98]. In line with this data, a study in the German population showed comparable results [99]. In the USA, the cost of PCSK9i needs to be reduced from 14.350 USD to 4,536 USD per annum in patients with heterozygous $\mathrm{FH}$ or atherosclerotic cardiovascular disease (ASCVD) to be considered cost-effective [100]. Alternatively, in the UK, NICE guidance identifies the LDL-C level at which 
Table 3. Lipid-lowering agents, prescription by therapeutic category in 2018 [98].

\begin{tabular}{|c|c|c|c|c|c|c|}
\hline & $\begin{array}{l}\text { Total } \\
\text { costs }\end{array}$ & $\begin{array}{l}\% \text { costs } \\
\text { of NHS }\end{array}$ & $\begin{array}{l}\text { Cost per } \\
\text { capita }(€)\end{array}$ & $\begin{array}{c}\% \\
17- \\
18 \\
\end{array}$ & $\begin{array}{c}\text { DDD*/ } \\
1000 \\
\text { Ab die }\end{array}$ & $\begin{array}{c}\% 17- \\
18\end{array}$ \\
\hline $\begin{array}{l}\text { Hypolipidemic } \\
\text { agents }\end{array}$ & 870.5 & 4.0 & 14.39 & -20.1 & 92.5 & 4.2 \\
\hline Statins & 477.8 & 2.2 & 7.90 & -25.0 & 77.4 & 3.3 \\
\hline Ezetimibe & 225.1 & 1.0 & 3.72 & -26.2 & 8.1 & 13.2 \\
\hline Omega 3 & 112.8 & 0.5 & 1.86 & 0.3 & 4.3 & 5.2 \\
\hline PCSK-9 inhibitors & 25.0 & 0.1 & 0.41 & $>100$ & 0.1 & $>100$ \\
\hline Fibrates & 22.9 & 0.1 & 0.38 & 2.5 & 2.7 & 3.0 \\
\hline MTP inhibitors & 6.9 & 0.0 & 0.11 & 16.3 & & \\
\hline Statins and fibrates & $<0.05$ & 0.0 & 0.00 & -76.0 & $<0.05$ & -75.0 \\
\hline
\end{tabular}

*defined daily dose

Table 4. Analysis of costs of lipid-lowering therapies in Italy 2017 vs. 2018 [98].

\begin{tabular}{lccc} 
Hypolipidemic agents & OSMED 2017 & OSMED 2018 & Difference \\
\hline Statins & $€ 638.300 .000$ & $€ 477.800 .000$ & $€ 160.500 .000$ \\
Ezetimibe & $€ 305.500 .000$ & $€ 225.100 .000$ & $€ 80.400 .000$ \\
Omega 3 & $€ 112.500 .000$ & $€ 112.800 .000$ & $€ 300.000$ \\
Fibrates & $€ 22.200 .000$ & $€ 22.900 .000$ & $€ 700.000$ \\
PCSK9i & $€ 6.600 .000$ & $€ 25.000 .000$ & $€ 18.400 .000$ \\
MTP inhibitors & $€ 5.900 .000$ & $€ 6.900 .000$ & $€ 1.000 .000$ \\
Total & $€ 1.091 .000 .000$ & $€ 870.500 .000$ & $€ 220.500 .000$ \\
\hline
\end{tabular}

incremental cost-effectiveness ratio (ICER) could be considered a cost-effective use of NHS recourses, based on maximum acceptable ICER [101].

\section{Effects of PCSK9i beyond the LDL}

Ever since the discovery of the role of PCSK9 on the regulation of the LDLR expression and LDL-C levels, understanding its interaction with other lipoproteins is still under investigation [2]. High-density lipoprotein (HDL) plays a central role in reverse cholesterol transport from peripheral tissues to the liver, as a mechanism to relieve cells from cholesterol burden. HDL precursors are formed by the liver and intestine through the absorption of free cholesterol from cell membranes, as APO1 activates cholesterol acyltransferase (LCAT) enzyme, which in turn esterifies the free cholesterol [102]. Thus, following different metabolic pathways, HDL particles interact with the hepatic SR-BI receptors resulting in selective uptake of cholesterol or CEPTmediated transfer of cholesterol from HDL to ApoB-containing lipoproteins. Under normal conditions, the rate of cholesteryl-ester transfer is relative to the rate of $\mathrm{HDL}$ and LDL catabolism. On the other hand, the degradation of LDLR by PCSK9 would increase the acceptor $A p o B$, enhancing the CEPT-mediated transfer of TG and cholesterol esters between plasma proteins. Specifically, the role of PCSK9 in HDL metabolism is still controversial. Fan et al. demonstrated how lipoproteins alter the capacity of PCSK9 to self-associate forming dimers and trimers, which in turn seem to increase the degradation of the LDLR. Based on this, in vitro, human and mice HDL significantly inhibited PCSK9 self-association as well as in vivo, the incubation of
PCSK9 with mouse serum demonstrated the association of PCSK9 with HDL and LDL, but not with VLDL [103]. Moreover, HEK293 cells expressing VLDLR and apoER2 exposed to PCSK9 showed decreased cellular levels of these receptors due to the downregulation of PCSK9, as both VLDLR and apoER2 bind to VLDL, it remains unclear whether these receptors play a role in human triglyceride metabolism [104]. However, more comprehensive studies are needed to reveal the potential association of PCSK9 with different lipoproteins. For instance, it has been shown the mechanism by which PCSK9 controls HDL-C levels by regulating the ApoE-containing $\mathrm{HDL}$. Based on preclinical data that need to be validated in the human condition, in PCSK9 KO mice and hLDLR transgenic mice, the concentrations of HDL-C and ApoE-containing HDL are decreased due to the overexpression of LDLR. However, apart from the fact that LDLR plays an essential role in the PCSK9 regulation of HDL-C, it has been shown that PCSK9 mediates the regulation on the presence of ApoE [105]. Following this, the reduction of $\mathrm{HDL}-\mathrm{C}$ concentration and cholesterol efflux by PCSK9 inactivation does not have any impact in early atherogenesis. In this context, the absence of ApoE increases by 2-fold the PCSK9-LDL bound while decreases by 1,5-fold the binding with HDL. Further studies will be necessary to evaluate the effect of HDL on PCSK9 assembly and the mechanism by which it occurs.

From a therapeutic standpoint, the results of clinical trials documented that patients treated with alirocumab experienced an HDL-C increase of 5-10\% [106]. According to a real-world study, PCSK9 inhibition treatment increased VLDL size significantly and reduced VLDL-associated lipoproteins apoE, apoCII, apoCIII; these findings reflect the higher clearance of atherogenic VLDL remnants by PCSK9i, as a promising approach in lowering cardiovascular risks beyond LDL-C reduction [107]. Besides, the data suggest that plasma levels of PCSK9 are predominantly related to the IDL fraction in subjects with dysbetalipoproteinemia due to apoE2/E2 homozygosity affecting plasma triglycerides (TGs) [108]. Another possible target is considered to be also the cholesterol ester transferase protein (CEPT) inhibitors, which block the exchange of cholesteryl esters from HDL to VLDL and LDL. The experimental data on liver tissue of mice fed with high cholesterol diet showed that CEPT-inhibitors as Anacetrapib negatively regulates gene expression of LDLR and PCSK9 through the inhibition of SREBP2, independently from CEPT inhibition [109]. A more comprehensive study would include in vivo the effect of CEPT inhibitors on LDL-C metabolism through LDLR/PCSK9 pathway. Together, yet it is not clear whether these treatments, including also the statins therapy, can increase the HDL concentration due to the ability to modulate the transfer of the cholesterol from HDL to LDL. More research is needed to understand the possible role of PCSK9 in the HDL- mediated reverse cholesterol transport. 


\section{Non-antibody approaches}

An alternative approach to the use of mAbs that blocks the PCSK9 function could be targeting the gene expression to suppress PCSK9 production. There are several non-antibody approaches under translation/development either in the suppression of the function of PCSK9 or inhibiting its gene expression (Figure 1).

\subsection{New drugs currently under clinical evaluation and development}

\subsubsection{Small interfering RNA (inclisiran)}

Among new therapies that aim to reduce the circulating PCSK9, small interfering RNA (siRNA) has been used to target the hepatic production of PCSK9. siRNA are short nucleotide RNA molecules that prevent translation by interfering with the expression of specific genes with complementary nucleotide sequences, thus affecting the degradation of mRNA [110]. Based on this approach, inclisiran is a long-acting synthetic siRNA, subcutaneously delivered, modified with a combination of phosphorothioate, 2'-O- methyl nucleotide and 2'-fluoro nucleotides to improve the molecule stability. The siRNA molecule directed against PCSK9 is conjugated with triantennary Nacetylgalactosamine carbohydrates, which binds the liver-asialoglycoprotein receptors, leading to preferential uptake of inclisiran into hepatocytes. According to preclinical data in nonhuman primates, a dose of $3 \mathrm{mg} / \mathrm{kg}$ resulted in $80 \%$ reduced in plasma PCSK9 levels and more than $60 \%$ LDL-C reduction, with the reduction lasting more than 30 days [111].

The phase 1 study tested the side-effect and pharmacodynamic profile of inclisiran administrated in single and multiple doses in healthy volunteers with an average LDL-C level of $100 \mathrm{mg} / \mathrm{dL}$. Following a single dose of $300 \mathrm{mg}$, reductions in PCSK9 level up to $83.8 \%$ and in LDL-C level of up to $59.7 \%$ were observed, as the administration of inclisiran every 3 or 6 months provides effective management of hypocholesteremia with no adverse effects and no significant changes in the QTc interval for heart rate [112]. In a follow-up, Orion-1 was a phase 2, double-blind, placebo-controlled, dose-finding study in 501 patients with a high risk of CVD with LDL-C levels > $70 \mathrm{mg} / \mathrm{dL}$ in the presence of atherosclerotic history or LDLC > $100 \mathrm{mg} / \mathrm{dL}$ in the absence of risk of ASCVD history. The studies report on day 180 a significant reduction of LDL-C up to $50 \mathrm{mg} / \mathrm{dL}$ level that was obtained with two doses of $300 \mathrm{mg}$ inclisiran at $48 \%$ of patients [113]. The ORION-7 study evaluated the effect of inclisiran on pharmacokinetics (PK) and pharmacodynamics (PD) in individuals with different degrees of renal impairment. According to data, individuals with renal impairment have greater exposure to plasma but without influence on the PD response [114]. Phase III clinical trials, ORION-10 and ORION-11, enrolled 1561 and 1617 patients with atherosclerotic cardiovascular disease or with equivalent risk who had LDL-C level elevated despite receiving statin therapy. A regimen of inclisiran injections on day 1, day 90 and every six months reduced levels of LDL-C by $49.2 \%$ to $52.2 \%$ compared to placebo as the level was decreased mostly in all patients receiving Inclisiran [115]. However, the total number of any potential benefits on cardiovascular outcomes was too small to conclude, a question that will be tested in ongoing cardiovascular trials. Following this, Orion-8 is a phase III extension of Orion-5,-9,-10,-11 measuring the effect of long term of Inclisiran in subjects in high cardiovascular risk and elevated LDL-C. Results from ORION-11 demonstrated that the rate of the adverse events was similar between placebo and treated arm as well as the cardiovascular endpoint such as cardiac death, cardiac arrest, $\mathrm{Ml}$ and stroke occurred in $7,8 \%$ of patients treated with Inclisiran, while it was $10.3 \%$ for the placebo group. To further establish the safety, tolerability and efficacy, ORION-4, a phase III double-blinded, will be conducted in 150 sites across the UK and USA to assess the effects of $300 \mathrm{mg} \mathrm{SC}$ at day Inclisiran on MACE among the subjects with ASCVD [116].

In summary, a siRNA therapeutic agent targeting PCSK9 represents a promising way in the management of hypercholesterolemia with significant reductions of circulating levels of both PCSK9 and LDL-C without adverse events in patients with renal impairment and diabetes.

\subsubsection{Antisense oligos}

A 14-mer oligonucleotide with locked nucleic acid (LNA) modifications can act as an antisense inhibitor complementary to PCSK9, decreasing intra and extracellular protein levels. The oligonucleotide contains $\beta$-D-oxy-LNA and eight deoxynucleotides with modified internucleotide to increase binding affinity and resistance. The preclinical data on mice and nonhuman primates have shown no rate-limiting toxicity on kidney and liver function without nephropathy signs. In human clinical trials, the starting dose in the randomized, double-blind, placebo-controlled study was $0.5 \mathrm{mg} / \mathrm{Kg}$ administered to healthy with slightly increased LDL-C levels. The primary endpoints resulted in decreased levels of plasma PCSK9 and LDL-C and ApoB. However, the highest dose of $5 \mathrm{mg} / \mathrm{Kg}$ reduced PCSK9 concentrations up to $50 \%$, and $25 \%$ of LDL-C compared to baseline but with transient renal tubular toxicity [117]. In the future, a better understanding of the molecular mechanism of SPC5001 is required to minimize the offtarget gene toxicity.

\subsection{Approaches under development}

Apart from the mentioned approaches, several different ways are undergoing to develop a new way to block PCSK9 [118]. Small-molecule inhibitors have been developed as a promising therapy to disrupt the interaction of the PCSK9 and LDLR or blocking the gene expression of PCSK9, with the advantage of oral administration and lower production costs than mAbs. A new cholesteryl ester transfer protein (CETP) inhibitor, K-312, reduces the PCSK9 expression and LDL-C level via a mechanism independent of CETP inhibition. Based on experimental data, in vivo, K-312 administered to rabbits after two weeks led to a $63 \%$ reduction of PCSK9's transcript 
levels in the liver and increased the high-density lipoproteins- cholesterol levels [119]. Another molecule PF846 has been proposed to block PCSK9 by interfering with the elongation phase of translation. The ribosome profiling showed that PF846 is a highly selective inhibitor of PCSK9 translation with no sign of toxicity in vivo [23]; however, the product was discontinued. Other known small molecules can reduce the PCSK9 synthesis or its function. Among them, only 0-304 (an activator of $5^{\prime}$ adenosine monophosphate-activated protein kinases (AMPK) developed by Betagenon) is in clinical trials for type 2 diabetes treatment; however, it can reduce the PCSK9 level significantly as well [120].

Annexin A2, an extracellular endogenous antagonist, binds to the C-terminal domain of PCSK9, inhibiting the degradation of LDLR. Thus, the adenoviral overexpression of AnxA2 in the liver results in an increase of LDLR levels. Meanwhile, an increase of 2-fold in circulating PCSK9 levels was observed in AnxA2 knockout mice [121]. Further studies at the level of clinical trials are necessary to identify the physiological role of Annexin A2.

CRISPR/Cas9 is a gene-editing tool that consists of a single guide RNA (gRNA) and Cas9 endonuclease as DNA-mediated cleavage generates a double-strand break that triggers DNA repair machinery [122]. The PCSK9 gene-editing technique has shown to disrupt the PCSK9 gene in mice liver, reducing the cholesterol level by $35-40 \%$ in knockout mice compared with wild-type mice [123]. Another recent work on a humanized mouse model expressing hPCSK9 specifically at liver showed the efficacy and feasibility of Cas9 guided gene editing of liver-specific PCSK9 [124]. Currently, due to being relatively straightforward from the experimental point of view, several preclinical activities are ongoing on the different animal models, such as nonhuman primates. However, the severe limitation here is the presence of many off-target mutations with a higher frequency rather than the intended mutation; thus, the designed sgRNA needs to be highly specific for long-term term benefit and safety in human subjects.

For long-term PCSK9 inhibition, the peptide-based vaccination stimulates the immune system to generate high-affinity antibodies as well as to block the ability of PCSK9 to bind to LDLR. AT04A, a peptide-based antiPCSK9 vaccine, mimics human mature PCSK9 protein, conjugated to a carrier protein that provides T-helper cell epitopes. The LDL-C and total cholesterol levels were reduced up to $30-50 \%$ in anti-PCSK9 immunized mice as the atherosclerotic plaques were down by $64 \%$ in the affected blood vessels [24]. However, the active immunization might cause cell-mediated cytotoxicity with non-specific cell destruction.

\section{Concluding remarks and future perspectives}

Anti-PCSK9 mAbs therapy has become one of the pillars in the control of dyslipidemias, specifically hypercholesterolemia. In this review, we have summarized the current state of understanding regarding the PCSK9 molecular mechanisms of action and the clinical use of the inhibition of this protein to manage the patients with high levels of apo B containing lipoproteins. Several new approaches to reduce PCSK9 activity/plasma levels are under development, and some will be shortly available for clinical use (such as inclisiran); some others are at the early stages of development or not biologicals. The related clinical studies have indicated that reducing PCSK9 is per se safe, off-target effects of the drug, however, need to be carefully studied.

\section{Expert opinion}

The use of biologicals in the therapy of hypercholesterolemia is a relatively recent addition to the medical armamentarium. However, even in the short term of availability of biologicals, they have profoundly contributed to our understanding about the role of LDL lowering at both the experimental and clinical levels. As of today, we have definitely been able to prove that the benefit of LDL-C lowering is independent of the approach that is being used but only proportional to LDL (Apo B) reduction. Further, deficient levels of LDL-C induced by therapy are safe and do not trigger specific adverse effects. Ultimately, we have been able to target specific pathways by different approaches (monoclonals vs. siRNAs) with the possibility of addressing whether tissue-specific reductions of PCSK9 have different effects as compared with general inhibition of PCSK9 in circulation. Targeting RNA is a challenging approach, although, for this, we do need long term safety data as the intracellular levels of PCSK9 are also likely to be reduced. Whether this effect has consequences on the hepatocyte needs further studies; to date, no specific adverse events have been reported. Finally, the link between insulin secretion and local PCSK9 production remains to be addressed to reconcile the genetic data with the data from the clinical trials.

\section{Funding}

The work of AL Catapano cited in this paper is supported in part by: Fondazione Cariplo [2015-0524 and 2015-0564]; H2020 REPROGRAM [PHC03-2015/667837-2]; ERANET ER-2017-2364981; PRIN 2017H5F943; Ministry of Health-IRCCS MultiMedica [GR-2011-02346974]; SISA Lombardia and Fondazione SISA; European Union's Horizon 2020 research and innovation program under the [ERA-Net Cofund action $N^{\circ} 727565$ (OCTOPUS project)]. This work has been supported by funds from the Italian Ministry of Health to IRCCS Multimedica (Ricerca Corrente).

\section{Declaration of interest}

AL Catapano has received honoraria, lecture fees, or research grants from: Akcea, Amgen, Astrazeneca, Eli Lilly, Genzyme, Kowa, Mediolanum, Menarini, Merck, Pfizer, Recordati, Sanofi, Sigma Tau, Medco and Amryt. The authors have no other relevant affiliations or financial involvement with any organization or entity with a financial interest in or financial conflict with the subject matter or materials discussed in the manuscript apart from those disclosed. 


\section{Reviewer disclosures}

Peer reviewers on this manuscript have no relevant financial relationships or otherwise to disclose.

\section{ORCID}

Amir Mohammad Malvandi (D) http://orcid.org/0000-0003-1243-2372

\section{References}

Papers of special note have been highlighted as either of interest ( $\bullet$ ) or of considerable interest $(\cdot \bullet)$ to readers

1. Norata GD, Tibolla G, Catapano AL. Targeting PCSK9 for hypercholesterolemia. Annu Rev Pharmacol Toxicol. 2014;54:273-293.

2. Norata GD, Tavori H, Pirillo A, et al. Biology of proprotein convertase subtilisin kexin 9: beyond low-density lipoprotein cholesterol lowering. Cardiovasc Res. 2016 Oct;112(1):429-442.

.- This review covers the aspects related to the interaction of PCSK9 with other lipoproteins and pathways.

3. Han $\mathrm{B}$, Eacho PI, Knierman MD, et al. Isolation and characterization of the circulating truncated form of PCSK9. J Lipid Res. 2014 Jul;55 (7):1505-1514.

4. Nishikido T, Ray KK. Non-antibody approaches to proprotein convertase subtilisin kexin 9 inhibition: siRNA, antisense oligonucleotides, adnectins, vaccination, and new attempts at small-molecule inhibitors based on new discoveries. Front Cardiovasc Med. 2018;5:199.

5. Lipari MT, Li W, Moran P, et al. Furin-cleaved proprotein convertase subtilisin/kexin type 9 (PCSK9) is active and modulates low density lipoprotein receptor and serum cholesterol levels. J Biol Chem. 2012 Dec 21;287(52):43482-43491.

- Experimental evidence on PCSK9 function and maturation steps.

6. Essalmani R, Susan-Resiga D, Chamberland A, et al. In vivo evidence that furin from hepatocytes inactivates PCSK9. J Biol Chem. 2011 Feb 11;286(6):4257-4263.

7. Lakoski SG, Lagace TA, Cohen JC, et al. Genetic and metabolic determinants of plasma PCSK9 levels. J Clin Endocrinol Metab. 2009 Jul;94(7):2537-2543.

8. Persson L, Cao G, Stahle L, et al. Circulating proprotein convertase subtilisin kexin type 9 has a diurnal rhythm synchronous with cholesterol synthesis and is reduced by fasting in humans. Arterioscler Thromb Vasc Biol. 2010 Dec;30(12):2666-2672.

9. Boyer M, Mitchell PL, Poirier P, et al. Impact of a one-year lifestyle modification program on cholesterol efflux capacities in men with abdominal obesity and dyslipidemia. Am J Physiol Endocrinol Metab. 2018 Oct 1;315(4):E460-E468.

10. Krysa JA, Ooi TC, Proctor SD, et al. Nutritional and lipid modulation of PCSK9: effects on cardiometabolic risk factors. J Nutr. 2017 Apr;147(4):473-481.

11. Rannikko J, Jacome Sanz D, Ortutay Z, et al. Reduced plasma PCSK9 response in patients with bacteraemia is associated with mortality. J Intern Med. 2019 Nov;286(5):553-561.

12. Baragetti A, Grejtakova D, Casula M, et al. Proprotein convertase subtilisin-kexin type-9 (PCSK9) and triglyceride-rich lipoprotein metabolism: facts and gaps. Pharmacol Res. 2018 Apr;130:1-11.

13. Abifadel M, Varret M, Rabes JP, et al. Mutations in PCSK9 cause autosomal dominant hypercholesterolemia. Nat Genet. 2003 Jun;34 (2):154-156.

- The first report was shedding light on the PCSK9 mechanism of action and its correlation with cholesterol level.

14. Cohen J, Pertsemlidis A, Kotowski IK, et al. Low LDL cholesterol in individuals of African descent resulting from frequent nonsense mutations in PCSK9. Nat Genet. 2005 Feb;37(2):161-165.
15. Brown MS, Goldstein JL. A receptor-mediated pathway for cholesterol homeostasis. Science. 1986 Apr 4;232(4746):34-47.

16. Leren TP. Sorting an LDL receptor with bound PCSK9 to intracellular degradation. Atherosclerosis. 2014 Nov;237(1):76-81.

17. Ference BA, Cannon CP, Landmesser $\mathrm{U}$, et al. Reduction of low density lipoprotein-cholesterol and cardiovascular events with proprotein convertase subtilisin-kexin type 9 (PCSK9) inhibitors and statins: an analysis of FOURIER, SPIRE, and the cholesterol treatment trialists collaboration. Eur Heart J. 2018 Jul 14;39 (27):2540-2545.

.- This work is a significant contribution to interpreting the clinical evidence regarding the efficacy of PCSK9 in the reduction of CVD risk.

18. Landmesser U, Chapman MJ, Stock JK, et al. New prospects for PCSK9 inhibition? Eur Heart J. 2018 Jul 14;39(27):2600-2601.

19. Catapano AL, Papadopoulos N. The safety of therapeutic monoclonal antibodies: implications for cardiovascular disease and targeting the PCSK9 pathway. Atherosclerosis. 2013 May;228(1):18-28.

- This review is a complete overview of different technical and clinical aspects related to the use of monoclonal antibodies for cardiovascular disorders.

20. Leiter LA, Teoh $H$, Kallend $D$, et al. Inclisiran Lowers LDL-C and PCSK9 irrespective of diabetes status: the ORION-1 randomized clinical trial. Diabetes Care. 2019 Jan;42(1):173-176.

21. Gupta N, Fisker N, Asselin MC, et al. A locked nucleic acid antisense oligonucleotide (LNA) silences PCSK9 and enhances LDLR expression in vitro and in vivo. PLoS One. 2010 May 17;5(5):e10682.

22. Lipovsek D. Adnectins: engineered target-binding protein therapeutics. Protein Eng Des Sel. 2011 Jan;24(1-2):3-9.

23. Li W, Ward FR, McClure KF, et al. Structural basis for selective stalling of human ribosome nascent chain complexes by a druglike molecule. Nat Struct Mol Biol. 2019 Jun;26(6):501-509.

24. Landlinger C, Pouwer MG, Juno C, et al. The AT04A vaccine against proprotein convertase subtilisin/kexin type 9 reduces total cholesterol, vascular inflammation, and atherosclerosis in APOE*3Leiden. CETP mice. Eur Heart J. 2017 Aug 21;38(32):2499-2507.

25. Stadler SL, Cook TJ. PCSK9 inhibitors and managing cost in the managed care setting. Am J Manag Care. 2017 Jun;23(9 Suppl):S149-s155.

26. Ly K, Saavedra YG, Canuel M, et al. Annexin A2 reduces PCSK9 protein levels via a translational mechanism and interacts with the M1 and M2 domains of PCSK9. J Biol Chem. 2014 Jun 20;289 (25):17732-17746.

27. Masuda Y, Yamaguchi S, Suzuki C, et al. Generation and characterization of a novel small biologic alternative to proprotein convertase subtilisin/kexin type 9 (PCSK9) antibodies, DS-9001a, albumin binding domain-fused anticalin protein. J Pharmacol Exp Ther. 2018 May;365(2):368-378.

28. Mitchell T, Chao G, Sitkoff D, et al. Pharmacologic profile of the Adnectin BMS-962476, a small protein biologic alternative to PCSK9 antibodies for low-density lipoprotein lowering. J Pharmacol Exp Ther. 2014 Aug;350(2):412-424.

29. Goldstein JL, Brown MS. The LDL receptor. Arterioscler Thromb Vasc Biol. 2009 Apr;29(4):431-438.

30. Poirier S, Mayer G, Benjannet $S$, et al. The proprotein convertase PCSK9 induces the degradation of low density lipoprotein receptor (LDLR) and its closest family members VLDLR and ApoER2. J Biol Chem. 2008 Jan 25;283(4):2363-2372.

31. Ouguerram K, Chetiveaux M, Zair Y, et al. Apolipoprotein B100 metabolism in autosomal-dominant hypercholesterolemia related to mutations in PCSK9. Arterioscler Thromb Vasc Biol. 2004 Aug;24 (8):1448-1453.

32. Sun $H$, Samarghandi $A$, Zhang $N$, et al. Proprotein convertase subtilisin/kexin type 9 interacts with apolipoprotein $B$ and prevents its intracellular degradation, irrespective of the low-density lipoprotein receptor. Arterioscler Thromb Vasc Biol. 2012 Jul;32 (7):1585-1595. 
33. Rashid S, Tavori $\mathrm{H}$, Brown PE, et al. Proprotein convertase subtilisin kexin type 9 promotes intestinal overproduction of triglyceride-rich apolipoprotein B lipoproteins through both low-density lipoprotein receptor-dependent and -independent mechanisms. Circulation. 2014 Jul 29;130(5):431-441.

34. Dubuc G, Chamberland A, Wassef $H$, et al. Statins upregulate PCSK9, the gene encoding the proprotein convertase neural apoptosis-regulated convertase-1 implicated in familial hypercholesterolemia. Arterioscler Thromb Vasc Biol. 2004 Aug;24(8):1454-1459.

35. Bjermo HID, Jullberg J, Dahlman I, et al. Effects of n-6 PUFAs compared with SFAs on liver fat, lipoproteins, and inflammation on abdominal obesity $>$ a randomized controlled trial. Am J Clin Nutr. 2012;95(5):1003-12

36. Galland L. Diet and inflammation. Nutr Clin Pract. 2010 Dec;25 (6):634-640

37. Ou J, Tu H, Shan B, et al. Unsaturated fatty acids inhibit transcription of the sterol regulatory element-binding protein-1c (SREBP-1C) gene by antagonizing ligand-dependent activation of the LXR. Proc Natl Acad Sci U S A. 2001;98(11):6027-6032.

38. Cao $\mathrm{A}, \mathrm{Wu} \mathrm{M}, \mathrm{Li} \mathrm{H}$, et al. Janus kinase activation by cytokine oncostatin $M$ decreases PCSK9 expression in liver cells. J Lipid Res. 2011 Mar;52(3):518-530.

39. Ruscica M, Ricci C, Macchi C, et al. Suppressor of cytokine signaling3 (SOCS-3) induces proprotein convertase subtilisin kexin type 9 (PCSK9) expression in hepatic HepG2 cell line. J Biol Chem. 2016 Feb 12;291(7):3508-3519.

40. Persson L, Gälman C, Angelin B, et al. Importance of proprotein convertase subtilisin/kexin type 9 in the hormonal and dietary regulation of rat liver low-density lipoprotein receptors. Endocrinology. 2009 Mar;150(3):1140-1146.

41. H DB L, Park SW, Lee HS, et al. Hepatocyte nuclear factor1 alpha plays a critical role in PCSK9 gene transcription and regulation by the natura hypocholesterolemic compound berberine. J Biol Chem. 2009;284:28885-28895.

42. Tao R, Xiong X, DePinho RA, et al. FoxO3 transcription factor and Sirt6 deacetylase regulate low density lipoprotein (LDL)-cholesterol homeostasis via control of the proprotein convertase subtilisin/ kexin type 9 (Pcsk9) gene expression. J Biol Chem. 2013 Oct 11;288(41):29252-29259.

43. Ai D, Chen $C$, Han $S$, et al. Regulation of hepatic LDL receptors by mTORC1 and PCSK9 in mice. J Clin Invest. 2012 Apr;122(4):12621270.

44. Li H, Liu J. The novel function of HINFP as a co-activator in sterolregulated transcription of PCSK9 in HepG2 cells. Biochem J. 2012 May 1;443(3):757-768.

45. Glerup S, Schulz R, Laufs U, et al. Physiological and therapeutic regulation of PCSK9 activity in cardiovascular disease. Basic Res Cardiol. 2017 May;112(3):32.

46. Poirier S, Mayer G. The biology of PCSK9 from the endoplasmic reticulum to lysosomes: new and emerging therapeutics to control low-density lipoprotein cholesterol. Drug Des Devel Ther. 2013;7:1135-1148.

47. Khan AR, James MN. Molecular mechanisms for the conversion of zymogens to active proteolytic enzymes. Protein Sci. 1998;7 (4):815-836.

48. Poirier S, Mamarbachi M, Chen WT, et al. GRP94 regulates circulating cholesterol levels through blockade of PCSK9-induced LDLR degradation. Cell Rep. 2015 Dec 15;13(10):2064-2071.

49. Miller EA, Beilharz TH, Malkus PN, et al. Multiple cargo binding sites on the COPII subunit Sec24p ensure capture of diverse membrane proteins into transport vesicles. Cell. 2003 Aug 22;114(4):497-509.

50. Chen XW, Wang H, Bajaj K, et al. SEC24A deficiency lowers plasma cholesterol through reduced PCSK9 secretion. Elife. 2013 Apr 9;2: e00444.

51. Gustafsen C, Kjolby M, Nyegaard M, et al. The hypercholesterolemia-risk gene SORT1 facilitates PCSK9 secretion. Cell Metab. 2014 Feb 4;19(2):310-318.
52. Mayer G, Poirier S, Seidah NG. Annexin A2 is a C-terminal PCSK9binding protein that regulates endogenous low density lipoprotein receptor levels. J Biol Chem. 2008 Nov 14;283(46):31791-31801.

53. Tomlinson B, Hu M, Zhang Y, et al. Alirocumab for the treatment of hypercholesterolemia. Expert Opin Biol Ther. 2017;17(5):633-643.

54. Khoury E, Brisson D, Gaudet D. Preclinical discovery and development of evolocumab for the treatment of hypercholesterolemia. Expert Opin Drug Discov. 2020 Apr;15(4):403-414.

55. Seidah NG, Benjannet $S$, Wickham L, et al. The secretory proprotein convertase neural apoptosis-regulated convertase 1 (NARC-1): liver regeneration and neuronal differentiation. Proc Natl Acad Sci U S A. 2003 Feb 4;100(3):928-933.

56. Maxwell KN, Breslow JL. Adenoviral-mediated expression of Pcsk9 in mice results in a low-density lipoprotein receptor knockout phenotype. Proc Natl Acad Sci U S A. 2004 May 4;101(18):71007105.

57. Chan JC, Piper DE, Cao Q, et al. A proprotein convertase subtilisin/ kexin type 9 neutralizing antibody reduces serum cholesterol in mice and nonhuman primates. Proc Natl Acad Sci U S A. 2009 Jun 16;106(24):9820-9825.

58. Lambert G, Sjouke B, Choque B, et al. The PCSK9 decade. J Lipid Res. 2012 Dec;53(12):2515-2524.

59. Manniello $M$, Pisano $M$. Alirocumab (Praluent): first in the new class of PCSK9 inhibitors. P T. 2016;41(1):28-53.

60. Kasichayanula S, Grover A, Emery MG, et al. Clinical pharmacokinetics and pharmacodynamics of evolocumab, a PCSK9 inhibitor. Clin Pharmacokinet. 2018 Jul;57(7):769-779.

61. Rise $P$, Tragni E, Ghezzi S, et al. Different patterns characterize Omega 6 and Omega 3 long chain polyunsaturated fatty acid levels in blood from Italian infants, children, adults and elderly. Prostaglandins Leukot Essent Fatty Acids. 2013 Sep;89(4):215-220.

62. Koren MJ, Lundqvist $P$, Bolognese $M$, et al. Anti-PCSK9 monotherapy for hypercholesterolemia: the MENDEL-2 randomized, controlled phase III clinical trial of evolocumab. J Am Coll Cardiol. 2014 Jun 17;63(23):2531-2540.

63. Koren MJ, Sabatine MS, Giugliano RP, et al. Long-term efficacy and safety of evolocumab in patients with hypercholesterolemia. J Am Coll Cardiol. 2019 Oct 29;74(17):2132-2146.

64. Giugliano RP, Desai NR, Kohli P, et al. Efficacy, safety, and tolerability of a monoclonal antibody to proprotein convertase subtilisin/kexin type 9 in combination with a statin in patients with hypercholesterolaemia (LAPLACE-TIMI 57): a randomised, placebocontrolled, dose-ranging, phase 2 study. Lancet. 2012 Dec 8;380 (9858):2007-2017.

65. McKenney JM, Koren MJ, Kereiakes DJ, et al. Safety and efficacy of a monoclonal antibody to proprotein convertase subtilisin/kexin type 9 serine protease, SAR236553/REGN727, in patients with primary hypercholesterolemia receiving ongoing stable atorvastatin therapy. J Am Coll Cardiol. 2012;59(25):2344-2353.

66. Raal F, Scott R, Somaratne R, et al. Low-density lipoprotein cholesterol-lowering effects of AMG 145, a monoclonal antibody to proprotein convertase subtilisin/kexin type 9 serine protease in patients with heterozygous familial hypercholesterolemia: the reduction of LDL-C with PCSK9 Inhibition in heterozygous familial hypercholesterolemia disorder (RUTHERFORD) randomized trial. Circulation. 2012 Nov 13;126(20):2408-2417.

67. Stein EA, Gipe D, Bergeron J, et al. Effect of a monoclonal antibody to PCSK9, REGN727/SAR236553, to reduce low-density lipoprotein cholesterol in patients with heterozygous familial hypercholesterolaemia on stable statin dose with or without ezetimibe therapy: a phase 2 randomised controlled trial. Lancet. 2012;380(9836):29-36.

68. Koren MJ, Scott R, Kim JB, et al. Efficacy, safety, and tolerability of a monoclonal antibody to proprotein convertase subtilisin/kexin type 9 as monotherapy in patients with hypercholesterolaemia (MENDEL): a randomised, double-blind, placebo-controlled, phase 2 study. Lancet. 2012 Dec 8;380(9858):1995-2006. 
69. Sullivan D, Olsson AG, Scott R, et al. Effect of a monoclonal antibody to PCSK9 on low-density lipoprotein cholesterol levels in statin-intolerant patients: the GAUSS randomized trial. JAMA. 2012 Dec 19;308(23):2497-2506.

70. Sabatine MS, Giugliano RP, Wiviott SD, et al. Efficacy and safety of evolocumab in reducing lipids and cardiovascular events. N Engl J Med. 2015 Apr 16;372(16):1500-1509.

.. The major clinical trial on Evolocumab

71. Robinson JG, Farnier M, Krempf $M$, et al. Efficacy and safety of alirocumab in reducing lipids and cardiovascular events. N Engl J Med. 2015 Apr 16;372(16):1489-1499.

72. Sabatine MS, Giugliano RP, Keech AC, et al. Evolocumab and clinical outcomes in patients with cardiovascular disease. N Engl J Med. 2017 May 4;376(18):1713-1722.

73. Giugliano RP, Pedersen TR, Park JG, et al. Clinical efficacy and safety of achieving very low LDL-cholesterol concentrations with the PCSK9 inhibitor evolocumab: a prespecified secondary analysis of the FOURIER trial. Lancet. 2017 Oct 28;390(10106):1962-1971.

74. Sabatine M Clinical benefit of evolocumab in patients with a story of MI: an analysis from FOURIER;. Presented at: American Heart Association 2017 Scioentific Session; 2017 November 13; Anaheim, CA.

75. Bonaca MP, Nault P, Giugliano RP, et al. Low-density lipoprotein cholesterol lowering with evolocumab and outcomes in patients with peripheral artery disease: insights from the FOURIER trial (further cardiovascular outcomes research with PCSK9 inhibition in subjects with elevated risk). Circulation. 2018 Jan 23;137 (4):338-350

76. Schwartz GG, Steg PG, Szarek M, et al. Alirocumab and cardiovascular outcomes after acute coronary syndrome. N Engl J Med. 2018 Nov 29:379(22):2097-2107.

.- The major clinical tiral on Alirocumab.

77. Ridker PM, Revkin J, Amarenco P, et al. Cardiovascular efficacy and safety of bococizumab in high-risk patients. N Engl J Med. $2017 \mathrm{Apr}$ 20;376(16):1527-1539.

78. Robinson JG, Nedergaard BS, Rogers WJ, et al. Effect of evolocumab or ezetimibe added to moderate- or high-intensity statin therapy on LDL-C lowering in patients with hypercholesterolemia: the LAPLACE-2 randomized clinical trial. JAMA. 2014;311(18):18701882.

79. Blom DJ, Hala T, Bolognese M, et al. A 52-week placebo-controlled trial of evolocumab in hyperlipidemia. N Engl J Med. 2014 May 8;370(19):1809-1819.

80. Stroes E, Colquhoun D, Sullivan D, et al. Anti-PCSK9 antibody effectively lowers cholesterol in patients with statin intolerance: the GAUSS-2 randomized, placebo-controlled phase 3 clinical trial of evolocumab. J Am Coll Cardiol. 2014;63(23):2541-2548.

81. Raal FJ, Stein EA, Dufour R, et al. PCSK9 inhibition with evolocumab (AMG 145) in heterozygous familial hypercholesterolaemia (RUTHERFORD-2): a randomised, double-blind, placebo-controlled trial. Lancet. 2015;385(9965):331-340.

82. Moriarty PM, Thompson PD, Cannon CP, et al. Efficacy and safety of alirocumab vs ezetimibe in statin-intolerant patients, with a statin rechallenge arm: the ODYSSEY ALTERNATIVE randomized trial. J Clin Lipidol. 2015 Nov-Dec;9(6):758-769.

83. Langlois MR, Nordestgaard BG, Langsted A, et al. Quantifying atherogenic lipoproteins for lipid-lowering strategies: consensusbased recommendations from EAS and EFLM. Clin Chem Lab Med. 2020 Mar 26;58(4):496-517.

- This work provides a new interpretation of the real case data from different clinical trials to conclude a direct relationship between the quantity of LDL in plasma and cardiovascular risk.

84. Julius U, Tselmin S, Schatz U, et al. Lipoprotein(a) and proprotein convertase subtilisin/kexin type 9 inhibitors. Clin Res Cardiol Suppl. 2019 April 01;14(S1):45-50.

85. Ridker PM, Tardif JC, Amarenco P, et al. Lipid-reduction variability and antidrug-antibody formation with bococizumab. N Engl J Med. 2017 Apr 20;376(16):1517-1526.
86. Roth EM, Goldberg AC, Catapano AL, et al. Antidrug antibodies in patients treated with alirocumab. N Engl J Med. 2017 Apr 20;376 (16):1589-1590.

87. Mefford MT, Rosenson RS, Cushman M, et al. PCSK9 variants, lowdensity lipoprotein cholesterol, and neurocognitive impairment: reasons for geographic and racial differences in stroke study (REGARDS). Circulation. 2018 Mar 20;137(12):1260-1269.

88. Colhoun HMGH, Robinson JG, Leiter LA, et al. No effect of PCSK9 inhibitor alirocumab on the incidence of diabetes in pooled analysis from 10 ODISSEY Phase 3 studies. Eur Heart J. 2016;37:29812989.

89. Sattar N, Preiss D, Robinson JG, et al. Lipid-lowering efficacy of the PCSK9 inhibitor evolocumab (AMG 145) in patients with type 2 diabetes: a meta-analysis of individual patient data. Lancet Diabetes Endocrinol. 2016 May;4(5):403-410.

90. Ference BA, Robinson JG, Brook RD, et al. Variation in PCSK9 and HMGCR and risk of cardiovascular disease and diabetes. N Engl J Med. 2016 Dec 1;375(22):2144-2153.

91. Schmidt AF, Swerdlow DI, Holmes MV, et al. PCSK9 genetic variants and risk of type 2 diabetes: a mendelian randomisation study. Lancet Diabetes Endocrinol. 2017 Feb;5(2):97-105.

92. Lotta LA, Sharp SJ, Burgess S, et al. Association between lowdensity lipoprotein cholesterol-lowering genetic variants and risk of type 2 diabetes: A meta-analysis. JAMA. 2016 Oct 4;316 (13):1383-1391.

93. Da Dalt $L$, Ruscica $M$, Bonacina $F$, et al. PCSK9 deficiency reduces insulin secretion and promotes glucose intolerance: the role of the low-density lipoprotein receptor. Eur Heart J. 2019 Jan 21;40 (4):357-U61.

- This paper provides experimental evidence for the role of PCSK9 in modulating insulin release by the pancreas

94. Malvandi AM, Loretelli C, Ben Nasr M, et al. Sitagliptin favorably modulates immune-relevant pathways in human beta cells. Pharmacol Res. 2019 Oct;148:104405.

95. Authors/Task Force Members; ESC Committee for Practice Guidelines (CPG); ESC National Cardiac Societies. 2019 ESC/EAS guidelines for the management of dyslipidaemias: lipid modification to reduce cardiovascular risk. Atherosclerosis.2020 Jan;292:160-162

96. Arrieta A, Page TF, Veledar E, et al. Economic evaluation of PCSK9 Inhibitors in reducing cardiovascular risk from health system and private payer perspectives. PLoS One. 2017;12(1):e0169761.

97. Kazi DS, Penko J, Coxson PG, et al. Updated Cost-effectiveness analysis of PCSK9 inhibitors based on the results of the FOURIER trial. Jama. 2017 Aug 22;318(8):748-750.

98. AIFA. The medicines utilisation monitoring centre. National Report on Medicines use in Italy. Italian Medicines Agency; 2018.

99. Dressel A, Schmidt B, Schmidt N, et al. Cost effectiveness of lifelong therapy with PCSK9 inhibitors for lowering cardiovascular events in patients with stable coronary artery disease: insights from the ludwigshafen risk and cardiovascular health cohort. Vascul Pharmacol. 2019;120:106566-106566.

100. Kazi DS, Moran AE, Coxson PG, et al. Cost-effectiveness of PCSK9 Inhibitor therapy in patients with heterozygous familial hypercholesterolemia or atherosclerotic cardiovascular disease. Jama. 2016 Aug 16;316(7):743-753.

101. NICE. Alirocumab for treating primary hypercholesterolaemia and mixed dyslipidaemia. Excellence. $\mathrm{NIfHaC}$, editor. London 2016.

102. Kwan BC, Kronenberg F, Beddhu S, et al. Lipoprotein metabolism and lipid management in chronic kidney disease. J Am Soc Nephrol. 2007 Apr;18(4):1246-1261.

103. Fan D, Yancey PG, Qiu S, et al. Self-association of human PCSK9 correlates with its LDLR-degrading activity. Biochemistry. 2008 Feb 12;47(6):1631-1639.

104. Druce I, Abujrad H, Ooi TC. PCSK9 and triglyceride-rich lipoprotein metabolism. J Biomed Res. 2015;29(6):429.

105. Choi S, Aljakna A, Srivastava U, et al. Decreased APOE-containing $\mathrm{HDL}$ subfractions and cholesterol efflux capacity of serum in mice lacking Pcsk9. Lipids Health Dis. 2013 Jul 24;12:112. 
106. Rosenson RS, Hegele RA, Fazio $S$, et al. The evolving future of PCSK9 inhibitors. J Am Coll Cardiol. 2018;72(3):314.

107. Hollstein T, Vogt A, Grenkowitz T, et al. Treatment with PCSK9 inhibitors reduces atherogenic VLDL remnants in a real-world study. Vascul Pharmacol. 2019 May;116:8-15.

108. Kwakernaak AJ, Lambert G, Dullaart RP. Plasma proprotein convertase subtilisin-kexin type 9 is predominantly related to intermediate density lipoproteins. Clin Biochem. 2014 May;47(7-8):679-682.

109. Dong $B$, Singh AB, Fung $C$, et al. CETP inhibitors downregulate hepatic LDL receptor and PCSK9 expression in vitro and in vivo through a SREBP2 dependent mechanism. Atherosclerosis. 2014;235(2):449-462.

110. Agrawal N, Dasaradhi PV, Mohmmed A, et al. RNA interference: biology, mechanism, and applications. Microbiol Mol Biol Rev. 2003 Dec;67(4):657-685.

111. Nair JK, Willoughby JL, Chan A, et al. Multivalent $\mathrm{N}$-acetylgalactosamine-conjugated siRNA localizes in hepatocytes and elicits robust RNAi-mediated gene silencing. J Am Chem Soc. 2014 Dec 10;136(49):16958-16961.

112. Fitzgerald $\mathrm{K}$, White $\mathrm{S}$, Borodovsky $\mathrm{A}$, et al. A highly durable RNAi therapeutic inhibitor of PCSK9. N Engl J Med. 2016;376(1):41-51.

113. Kosmas CE, Munoz Estrella A, Sourlas A, et al. Inclisiran: $A$ new promising agent in the management of hypercholesterolemia. Diseases. 2018 Jul 13;6:3.

114. Wright RS, Collins MG, Stoekenbroek RM, et al. Effects of renal impairment on the pharmacokinetics, efficacy, and safety of inclisiran: an analysis of the ORION-7 and ORION-1 studies. Mayo Clin Proc. 2020 Jan;95(1):77-89.

115. Ray KK, Wright RS, Kallend D, et al. Two phase 3 trials of inclisiran in patients with elevated LDL cholesterol. N Engl J Med. 2020;382 (16):1507-1519.

.. The output of two larg scale clinical trials on Inclisiran.
116. German CA, Shapiro MD. Small interfering RNA therapeutic inclisiran: A new approach to targeting PCSK9. BioDrugs. 2020 Feb 01;34(1):1-9.

117. van Poelgeest EP, Hodges MR, Moerland M, et al. Antisensemediated reduction of proprotein convertase subtilisin/kexin type 9 (PCSK9): a first-in-human randomized, placebocontrolled trial. $\mathrm{Br} J$ Clin Pharmacol. 2015 Dec;80(6): 1350-1361.

118. Mullard A. Nine paths to PCSK9 inhibition. Nat Rev Drug Discov. 2017 Apr 28;16(5):299-301.

119. Miyosawa K, Watanabe $Y$, Murakami K, et al. New CETP inhibitor K312 reduces PCSK9 expression: a potential effect on LDL cholesterol metabolism. Am J Physiol Endocrinol Metab. 2015 Jul 15;309 (2):E177-90.

120. Steneberg P, Lindahl E, Dahl U, et al. PAN-AMPK activator O304 improves glucose homeostasis and microvascular perfusion in mice and type 2 diabetes patients. JCl Insight. 2018 Jun 21;3:12.

121. Seidah NG, Poirier $S$, Denis $M$, et al. Annexin $A 2$ is a natural extrahepatic inhibitor of the PCSK9-induced LDL receptor degradation. PLoS One. 2012;7(7):e41865.

122. Porteus M. Genome editing: a new approach to human therapeutics. Annu Rev Pharmacol Toxicol. 2016 Jan 06;56 (1):163-190.

123. Rashid S, Curtis DE, Garuti R, et al. Decreased plasma cholesterol and hypersensitivity to statins in mice lacking Pcsk9. Proc Natl Acad Sci U S A. 2005 Apr 12;102(15):5374-5379.

124. Carreras A, Pane LS, Nitsch R, et al. In vivo genome and base editing of a human PCSK9 knock-in hypercholesterolemic mouse model. BMC Biol. 2019;17(1):4-4. DOI:10.1186/s12915018-0624-2 